\title{
Sintesis Komposit Polianilin-Karbon Aktif dari Tongkol Jagung sebagai Elektrolit Padat Pada Baterai
}

\author{
Lela Mukmilah Yuningsih, Dikdik Mulyadi, Yusri Mutia Fauziyah \\ Program Studi Kimia, Fakultas Sains dan Teknologi, Universitas Muhammadiyah Sukabumi, Jl. R Syamsudin \\ SH No. 50 Kota Sukabumi, 43113 \\ Email: lelathea@ummi.ac.id
}

Received: March 2018; Revised: August 2018; Accepted: November 2018; Available Online: November 2018

\begin{abstract}
Abstrak
Komposit polianilin-karbon aktif disintesis dengan menggunakan metode polimerisasi anilin secara oksidasi kimia serta variasi suhu karbonisasi $800^{\circ} \mathrm{C}$ dan $1000^{\circ} \mathrm{C}$. Komposit polianilin-karbon aktif dikarakterisasi nilai konduktivitas, gugus fungsi, kristalinitas, morfologi, komposisi dan besaran listriknya dengan analisis LCRmeter, FTIR, XRD, SEM-EDX dan multimeter digital. Nilai konduktivitas komposit polianilin-karbon suhu karbonisasi $800{ }^{\circ} \mathrm{C}$ dan $1000{ }^{\circ} \mathrm{C}$ berturut-turut yaitu $0.718 \mathrm{~S} / \mathrm{cm}$ dan $1.1003 \mathrm{~S} / \mathrm{cm}$. Komposit polianilin-karbon aktif 800 dan Polianilin-Karbon aktif 1000 menunjukkan adanya pita serapan yang identik dengan PANI. Bilangan gelombang yang muncul pada komposit PANI-karbon aktif 800 dan PANI-karbon aktif 1000 merupakan puncak karakteristik dari PANI dimana bilangan gelombang $1562 \mathrm{~cm}^{-1}, 1558 \mathrm{~cm}^{-1}$ merupakan vibrasi $\mathrm{C}=\mathrm{N}$ dan $1479 \mathrm{~cm}^{-1}, 1475 \mathrm{~cm}^{-1}$ merupakan vibrasi ulur $\mathrm{C}=\mathrm{C}$ dengan derajat kristalinitas PANI-Karbon aktif 800 yaitu $23.31 \%$ dan PANI-Karbon aktif 1000 yaitu $37.68 \%$. Analisis morfologi permukaan dan kandungan unsur komposit menggunakan SEM-EDX menunjukkan bahwa partikel polianilin tumbuh pada serat karbon aktif dan terbebas dari unsur pengotor. Tegangan dan Arus yang dihasilkan PANI-Karbon 800 dan PANI-Karbon 1000 berturut-turut tegangan 1.09 Volt dengan arus $19.74 \mathrm{~mA}$ dan 1.15 Volt dengan arus $19.98 \mathrm{~mA}$.
\end{abstract}

Kata kunci: Karbon aktif, komposit, konduktivitas, polianilin.

\begin{abstract}
The polyaniline-activated carbon composites are synthesized using aniline chemical oxidation polymerization methods as well as variations in carbonization temperature of $800{ }^{\circ} \mathrm{C}$ and $1000{ }^{\circ} \mathrm{C}$. The polyaniline-activated carbon composites are characterized by their value of conductivity, functional groups, crystallinity, morphology, composition and electrical quantities by LCR-meter analysis, FTIR, XRD, SEM-EDX and digital multimeters. The conductivity value of composite polyanilin-activated carbon with carbonization temperature of $800^{\circ} \mathrm{C}$ and $1000{ }^{\circ} \mathrm{C}$ are $0.718 \mathrm{~S} / \mathrm{cm}$ and $1.1003 \mathrm{~S} / \mathrm{cm}$. Polyaniline-activated carbon 800 composite and Polyaniline-activated carbon 1000 composite showed absorption bands acoording to PANI. The wave number that appear on PANIactivated carbon 800 composite and PANI-activated carbon 1000 peak is characteristic of PANI where the wave number $1562 \mathrm{~cm}^{-1}, 1558 \mathrm{~cm}^{-1}$ is the vibration of the $\mathrm{C}=\mathrm{N}$ and $1479 \mathrm{~cm}^{-1}, 1475 \mathrm{~cm}^{-1}$ is the vibration of the $\mathrm{C}=\mathrm{C}$ with slacking off the degree of crystallinity PANI-activated carbon 800 i.e. $23.31 \%$ and PANI-activated Carbon 1000 i.e. $37.68 \%$. Analysis of surface morphology and composite element content using SEM-EDX shows that particles of polianilin grows on active carbon fiber and free from impurity. The resulting voltage and current both PANI-Carbon 800 and PANI-carbon 1000 are 1.09 volt $19.74 \mathrm{~mA}$ and 1.15 Volts $19.98 \mathrm{~mA}$.
\end{abstract}

Keywords: Activated carbon, composite, conductivity, polyaniline.

DOI: http://10.15408/jkv.v4i2.7390 


\section{PENDAhuluan}

Karbon aktif lebih sering diaplikasikan sebagai adsorben. Selain diaplikasikan sebagai adsorben karbon juga memiliki fungsi lain yang jauh lebih memiliki nilai jual yang tinggi yaitu sebagai bahan karbon untuk baterai kendaraan berbasis energi listrik, sebagai pengganti bahan aditif elektroda pada baterai, juga bahan elektrolit padat baterai. Syarat bahan agar dapat dijadikan elektroda maupun elektrolit padat pada baterai adalah memiliki nilai konduktivitas yang tinggi, karena dengan semakin tinggi nilai konduktivitas suatu bahan maka semakin baik bahan tersebut dalam menghantarkan arus (Destyorini et al. 2010)

Menurut Yuningsih et al. (2016) Nilai konduktivitas karbon aktif tongkol jagung yaitu berkisar antara 0.8351-0.8622 S/cm. Nilai konduktivitas ini relatif masih rendah untuk dapat diaplikasikan sebagai elektrolit padat. Untuk meningkatkan nilai konduktivitas dari karbon aktif dapat dilakukan pengompositan karbon aktif (Surianty et al., 2013).

Komposit karbon aktif dapat dibuat dengan menambahkan sejenis polimer konduktif dengan karbon aktif (Nurdiati 2015). Polianilin (PANI) merupakan polimer konduktif yang sering digunakan dikarenakan polianilin memiliki sifat elektrokimia, listrik dan optis yang unik serta mempunyai stabilitas termal yang baik (Surianty et al. 2013). Nurdiati (2015) telah berhasil mensintesis komposit PANI-karbon dari tempurung kemiri sebagai bahan elektrode kapasitor dengan nilai konduktivitas listrik sebesar $5.7 \times 10^{-5} \mathrm{~S} / \mathrm{cm}$.

Tujuan penelitian ini untuk mengetahui nilai konduktivitas, besaran listrik, karakteristik gugus fungsi, kristalinitas, morfologi dan komposisi komposit PANI-karbon dengan variasi suhu karbonisasi karbon aktif $800{ }^{\circ} \mathrm{C}$ dan $1000{ }^{\circ} \mathrm{C}$.

\section{METODE PENELITIAN Alat dan Bahan}

Alat-alat yang digunakan adalah neraca analitik, stirer, oven, furnace, peralatan kaca yang umum di laboratorium, LCR-meter HIOKI 3522-50 untuk mengukur konduktivitas, FTIR Bruker, XRD Shimadzu 7000, SEM-EDX ZEISS EVO 50 dan Multimeter Digital DEKKO DM-133D.

Bahan-bahan yang digunakan adalah tongkol jagung, akuades, anilin, kalium dikromat, asam klorida dan aseton.

\section{Sintesis Karbon Aktif Tongkol Jagung}

Sintesis arang aktif mengacu pada Nyimas et al. (2014). Tongkol jagung dipotongpotong dan dicuci, setelah itu dioven untuk pada suhu $105{ }^{\circ} \mathrm{C}$ selama $12 \mathrm{jam}$. Selanjutnya, tongkol jagung dimasukkan ke dalam furnace, kemudian dipanaskan pada suhu $800^{\circ} \mathrm{C}$ dan $1000^{\circ} \mathrm{C}$ selama $2 \mathrm{jam}$. Setelah itu arang yang dihasilkan didinginkan di dalam furnace selama 12 jam, dan dikeringkan dalam oven selama 24 jam pada suhu $105{ }^{\circ} \mathrm{C}$. Kemudian arang di aktivasi secara fisika pada suhu $600{ }^{\circ} \mathrm{C}$ selama 2 jam.

\section{Sintesis Komposit PANI-Karbon aktif}

Polimerisasi anilin mengacu pada penelitian Nur (2017). 0.2 gram karbon aktif ditambahkan anilin dengan rasio bobot anilin terhadap karbon aktif (ba:bk) $5: 1 ; 10: 1 ; 15: 1$ dan 20:1. Campuran diaduk selama 1 jam kemudian dilarutkan kedalam $75 \mathrm{~mL}$ larutan $\mathrm{HCl}$. Larutan inisiator dibuat dengan melarutkan $\mathrm{K}_{2} \mathrm{Cr}_{2} \mathrm{O}_{7}$ dalam $75 \mathrm{~mL}$ larutan $\mathrm{HCl}$. Konsentrasi $\mathrm{HCl}$ yang digunakan adalah $3 \mathrm{M}$. Perbandingan mol inisiator terhadap monomer sebesar 1:2. Kedua larutan dicampur dan diaduk selama 30 menit. Campuran didiamkan selama 24 jam. Hasil komposit PANI-karbon aktif disaring kemudian dicuci dengan larutan $\mathrm{HCl}$ $0.2 \mathrm{M}$ dan aseton selanjutnya dikeringkan dalam oven selama 24 jam pada suhu $60{ }^{\circ} \mathrm{C}$. Komposit PANI-Karbon dikarakterisasi dengan analisis LCR-meter, FTIR, SEM-EDX dan XRD.

\section{Karakterisasi Besaran Listrik Komposit PANI-Karbon}

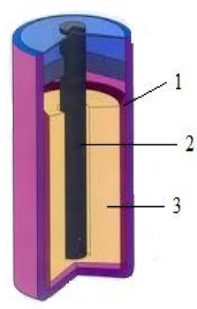

Gambar 1. Model baterai komposit PANI-Karbon (William et al. 2014)

Keterangan :

1. Anoda : Terbuat dari $\mathrm{Zn}$ (seng)

2. Katoda : Terbuat dari Grafit/Karbon

3. Elektrolit : Elektrolit padat komposit PANI-Karbon

Pengukuran arus dan tegangan komposit PANI-karbon dilakukan dengan menggunakan multimeter digital DEKKO DM- 
133D. Pertama disiapkan baterai yang sudah tidak digunakan, dikeluarkan isi dari baterai tersebut, lalu dimasukan komposit PANIkarbon kedalam baterai dan dipadatkan isinya sampai penuh kemudian ditutup kembali seperti semula. Kemudian diukur tegangan dan arusnya dengan multimeter digital. Adapun model baterai komposit PANI-Karbon ditunjukan pada gambar 1.

\section{HASIL DAN PEMBAHASAN \\ Sintesis PANI-Karbon aktif}

Sintesis komposit PANI-karbon dilakukan dengan menggunakan metode polimerisasi anilin secara oksidasi kimia. Menurut Hadiana (2012) polimerisasi anilin secara oksidasi kimia dapat dilakukan dengan cara oksidasi anilin oleh inisiator pada media larutan asam. Adapun mekanisme polimerisasi anilin secara oksidasi kimia ditunjukan pada gambar 2.

Tahap 1. Inisiasi

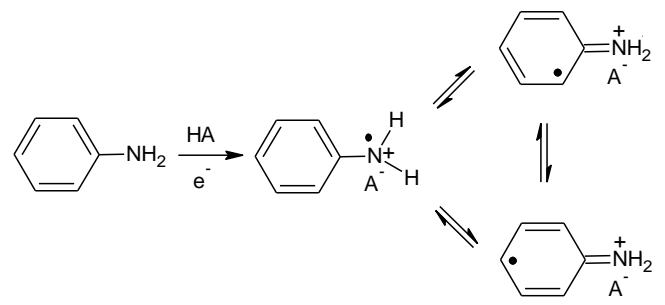

Tahap 2. Kopling radikal

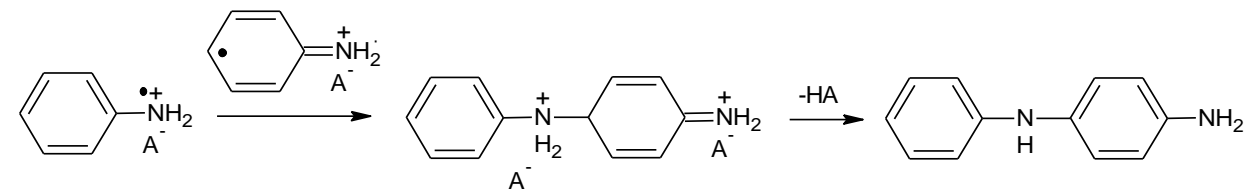

Tahap 3. Propagasi rantai

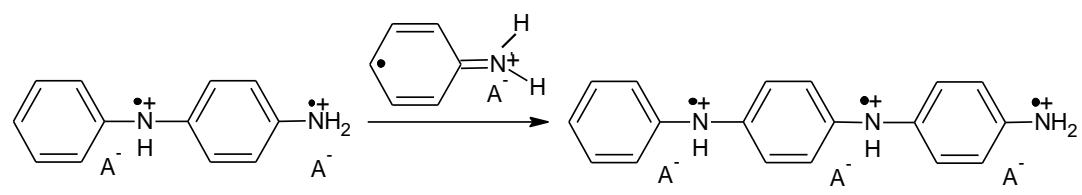

Tahap 4. Terminasi

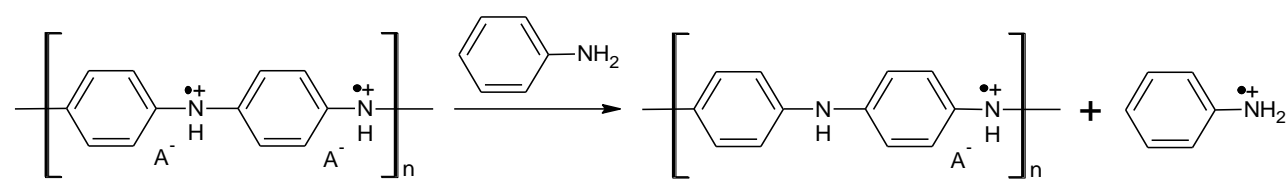

Gambar 2. Mekanisme reaksi polimerisasi (Taylor 2009)

\section{Karakterisasi Komposit PANI-Karbon Aktif}

Nilai konduktivitas karbon aktif dan PANI-Karbon dengan berbagai rasio bobot komposit pada frekuensi $10000 \mathrm{~Hz}$ ditunjukkan pada tabel 1. Nilai konduktivitas komposit PANI-Karbon semakin meningkat seiring meningkatnya suhu karbonisasi dari karbon aktif, hal ini disebabkan karena meningkatnya suhu karbonisasi menyebabkan derajat kristalinitas semakin meningkat yang mana mengindikasikan pembentukan struktrur atom karbon yang semakin teratur sehingga menyebabkan peningkatan konduktivitas (Destyorini et al., 2010). 
Meningkatnya rasio anilin menyebabkan penurunan nilai konduktivitas, hal ini dikarenakan pada bobot anilin yang tinggi monomer anilin tidak terprotonasi secara sempurna atau menyisakan atom nitrogen imin $(=\mathrm{N}-)$ yang tidak terprotonasi dalam PANI (Rao et al. 2002). Nilai konduktivitas komposit optimum yang diperoleh pada komposit PANIKarbon aktif dengan suhu karbonisasi $800{ }^{\circ} \mathrm{C}$ dan $1000{ }^{\circ} \mathrm{C}$ yakni pada rasio anilin-karbon 5:1 yaitu $0.718 \mathrm{~S} / \mathrm{cm}$ dan $1.1003 \mathrm{~S} / \mathrm{cm}$.

Hasil pengujian dengan menggunakan FTIR diperoleh seperti ditunjukan oleh gambar 3. Karbon aktif dengan karbonisasi $800{ }^{\circ} \mathrm{C}$ dan $1000{ }^{\circ} \mathrm{C}$ menunjukan adanya vibrasi $-\mathrm{OH}$ pada $3428 \mathrm{~cm}^{-1}$ dan $3427 \mathrm{~cm}^{-1}$. Serapan pada bilangan gelombang $2924 \mathrm{~cm}^{-1}$ dan $2930 \mathrm{~cm}^{-1}$ menunjukan adanya ikatan $\mathrm{C}-\mathrm{H}$ dari senyawa aromatik, serapan pada bilangan gelombang $1113 \mathrm{~cm}^{-1}$ dan $1111 \mathrm{~cm}^{-1}$ menujukan adanya vibrasi $\mathrm{C}-\mathrm{O}$, dan serapan pada bilangan gelombang $1626 \mathrm{~cm}^{-1}$ menunjukan adanya ikatan C=C. Komposit PANI-karbon aktif 800 dan PANI-Karbon aktif 1000 menunjukkan adanya pita serapan yang identik dengan PANI. Bilangan gelombang $1562 \mathrm{~cm}^{-1}, 1558 \mathrm{~cm}^{-1}$, $1479 \mathrm{~cm}^{-1}$ dan $1475 \mathrm{~cm}^{-1}$ yang muncul pada komposit PANI-karbon aktif 800 dan PANIkarbon aktif 1000 merupakan puncak karakteristik dari PANI dimana $1562 \mathrm{~cm}^{-1}, 1558$ $\mathrm{cm}^{-1}$ merupakan vibrasi $\mathrm{C}=\mathrm{N}$ dan $1479 \mathrm{~cm}^{-1}$, $1475 \mathrm{~cm}^{-1}$ merupakan vibrasi ulur $\mathrm{C}=\mathrm{C}$. Sedangkan puncak karakteristik dari PANI konduktif yakni pada bilangan gelombang 1142 $\mathrm{cm}^{-1}$ dan $1136 \mathrm{~cm}^{-1}$ (Sharma et al. 2015).

Tabel 1. Nilai konduktivitas Karbon Aktif dan Komposit PANI-Karbon aktif pada frekuensi $10000 \mathrm{~Hz}$

\begin{tabular}{|c|c|c|c|c|}
\hline \multicolumn{2}{|c|}{ Konduktivitas Karbon aktif (S/cm) } & \multirow{2}{*}{$\begin{array}{c}\text { Rasio } \\
\text { Anilin- } \\
\text { Karbon }\end{array}$} & \multicolumn{2}{|c|}{ Konduktivitas PANI-Karbon aktif (S/cm) } \\
\hline Karbon aktif 800 & Karbon aktif 1000 & & $\begin{array}{c}\text { PANI-Karbon aktif } \\
800\end{array}$ & $\begin{array}{c}\text { PANI-Karbon aktif } \\
1000\end{array}$ \\
\hline \multirow{4}{*}{0.00172} & \multirow{4}{*}{0.00775} & $5: 1$ & 0.718 & 1.1003 \\
\hline & & $10: 1$ & 0.0722 & 0.1575 \\
\hline & & $15: 1$ & 0.0179 & 0.0842 \\
\hline & & $20: 1$ & 0.00722 & 0.0249 \\
\hline
\end{tabular}

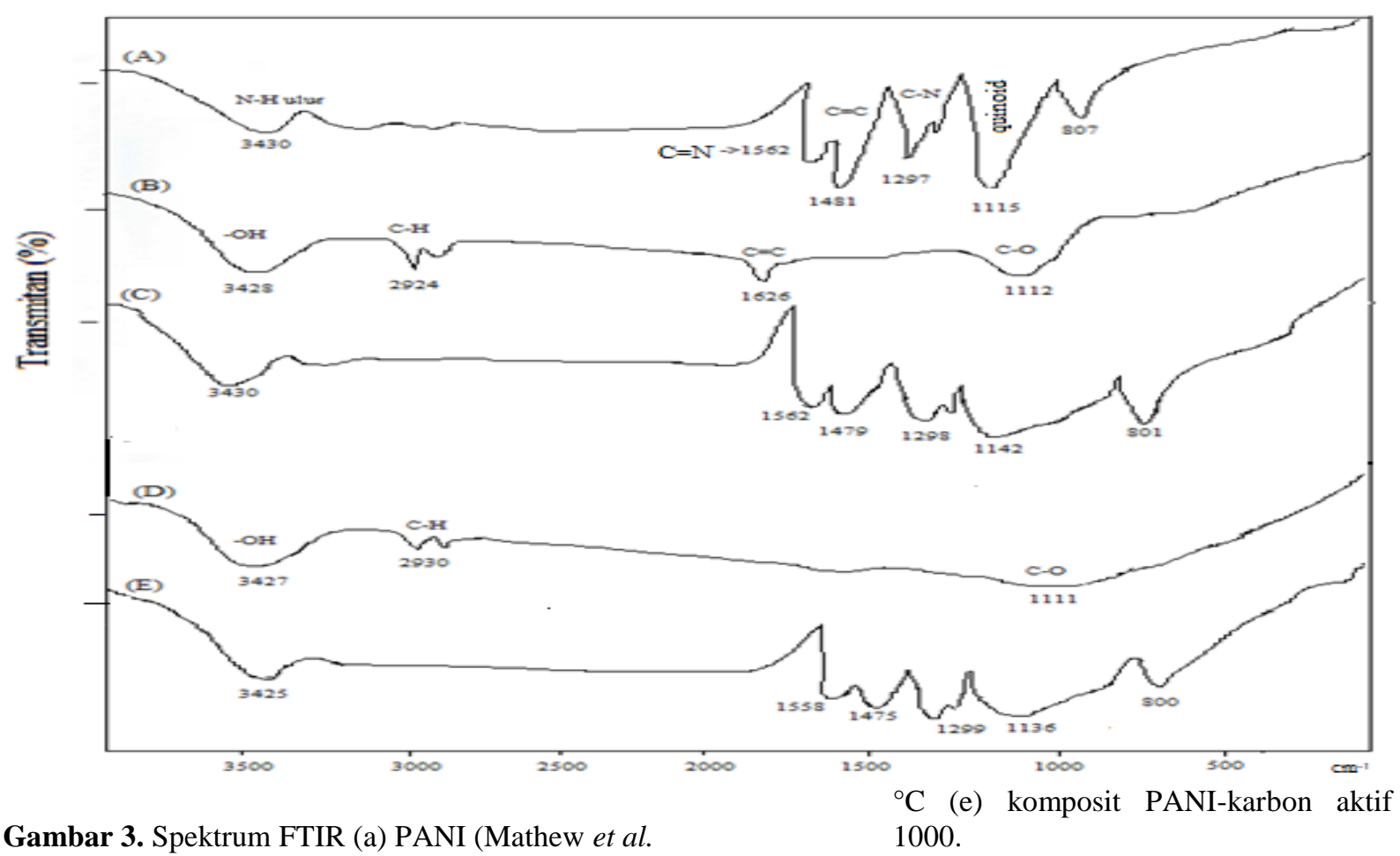

2013) (b) karbon $800{ }^{\circ} \mathrm{C}$ (c) komposit

PANI-karbon aktif 800 (d) karbon 1000 
Hasil XRD komposit PANI-karbon ditunjukan pada gambar 4. Puncak difraksi karbon yang dihasilkan yaitu pada $2 \theta=23.63^{\circ}$ dan $2 \theta=$ $44.4^{\circ}$ dengan intensitas yang kecil. Menurut Sonibare et al., (2010) melebarnya puncak difraksi sinar-X pada sudut $2 \theta=10^{\circ}-30^{\circ}$ dan munculnya puncak di $2 \theta=24^{\circ}$ mengindikasikan bahwa karbon aktif yang dihasilkan merupakan turbostatic, yang mana bentuk turbostatic mendekati bentuk kristalin dari karbon. Menurut Sharma et al. (2015) struktur semikristalin dari PANI berada pada nilai $2 \theta=20.4^{\circ}$ dan $25.3^{\circ}$ yang merupakan PANI dalam bentuk garam emeraldin.

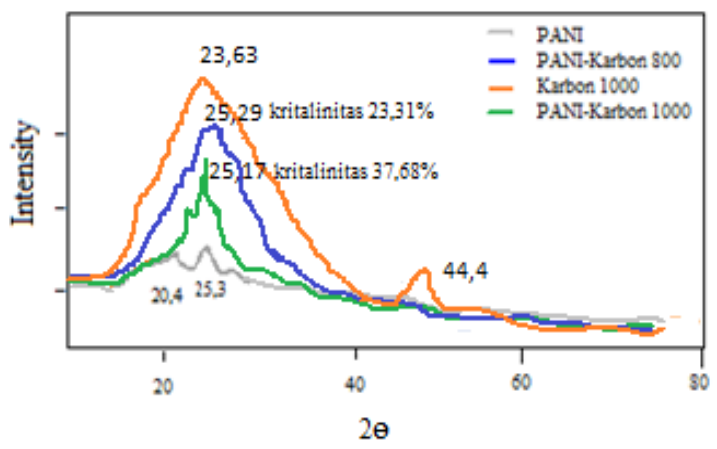

Gambar 4. Spektra XRD PANI (Sharma et al., 2015), Karbon, PANI-Karbon 800 dan PANI-Karbon 1000

Puncak difraksi yang diperoleh untuk komposit PANI-karbon aktif 800 dan PANIKarbon aktif 1000 berturut-turut yaitu pada nilai $2 \theta=25.29^{\circ}$ dan $25.17^{\circ}$ yang merupakan karakteristik PANI dalam komposit PANIKarbon dan puncak khas karbon pada komposit PANI-karbon yaitu pada $2 \theta=23.93^{\circ}$. Hal ini menunjukan bahwa PANI terdispersi pada permukaan karbon membentuk komposit PANIkarbon dengan derajat kristalinitas PANIKarbon aktif 800 yaitu $23.31 \%$ dan PANIKarbon aktif 1000 yaitu $37.68 \%$.

Mikrograf SEM PANI-karbon (gambar 5) yang disintesis menunjukkan pembentukan butiran yang mengumpal dan tidak teratur dari PANI, hal ini sesuai dengan yang dilaporkan oleh Sharma et al. (2015) dimana polimerisasi PANI ke karbon menyebabkan pengendapan PANI pada permukaan karbon sehingga permukaan karbon menjadi kasar.

Tabel 2 menunjukkan komposisi unsur yang terkandung dalam komposit PANI-karbon adalah $\mathrm{C}, \mathrm{N}, \mathrm{O}$ dan $\mathrm{Cl}$. $\mathrm{C}$ dan $\mathrm{O}$ merupakan hidrokarbon penyusun karbon aktif, sedangkan
$\mathrm{N}$ merupakan unsur penyusun PANI dan $\mathrm{Cl}$ merupakan anion hasil pendopingan PANI oleh $\mathrm{HCl}$. Berdasarkan hasil yang diperoleh komposit PANI-karbon terbebas dari pengotor.
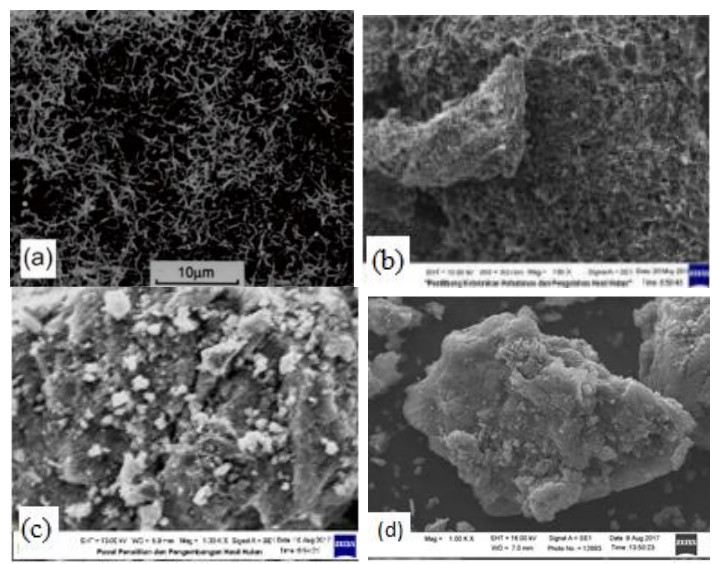

Gambar 5. Mikrograf SEM (a) PANI pada perbesaran 1000x (Wallace et al. 2003) (b) karbon tongkol jagung (Yuningsih et al. 2016) (c) komposit PANI-Karbon 800 (d) komposit PANI-karbon 1000.

Tabel 2. Komposisi Komposit PANI-Karbon

\begin{tabular}{lll}
\hline \multicolumn{1}{c}{ Komposit } & \multicolumn{1}{c}{ Unsur } & Berat \% \\
\hline PANI- & Karbon $(\mathrm{C})$ & 50.11 \\
Karbon800 & Nitrogen (N) & 20.88 \\
& Oksigen (O) & 7.23 \\
& Klor (Cl) & 21.78 \\
PANI- & Karbon (C) & 70.54 \\
Karbon1000 & Nitrogen (N) & 16.89 \\
& Oksigen (O) & 6.41 \\
& Klor (Cl) & 6.16 \\
\hline
\end{tabular}

Komposit PANI-karbon diuji besaran listriknya dengan menggunakan alat multimeter digital. Komposit PANI-Karbon 800 menghasilkan tegangan $1.09 \mathrm{~V}$ dan arus sebesar 19.74 mA. Sedangkan komposit PANI-Karbon 1000 menghasilkan tegangan $1.15 \mathrm{~V}$ dengan arus $19.98 \mathrm{~mA}$. Tegangan dan arus yang dihasilkan komposit PANI-karbon aktif 1000 lebih besar dibandingkan komposit PANIkarbon aktif 800 hal ini mengindikasikan bahwa nilai konduktivitas dan derajat kristalinitas berpengaruh terhadap besaran listrik yang dihasilkan, dimana nilai konduktivitas dan derajat kristalinitas yang besar menghasilkan besaran listrik yang besar pula. 


\section{SIMPULAN}

Nilai konduktivitas PANI-Karbon 800 dan PANI-Karbon 1000 berturut-turut 0.718 $\mathrm{S} / \mathrm{cm}$ dan $1.1003 \mathrm{~S} / \mathrm{cm}$ dengan tegangan kerja 1.09 Volt dengan arus $19.74 \mathrm{~mA}$ dan 1.15 Volt dengan arus $19.98 \mathrm{~mA}$.

\section{DAFTAR PUSTAKA}

Destyorini F, Suhandi A, Subhan A, dan Indayaningsih I. 2010. Pengaruh suhu karbonasi terhadap struktur dan konduktivitas listrik arang serabut kelapa. Jurnal Fisika. 10(02): 122-132

Hadiana D. 2012. Polimerisasi Anilin Oleh Horseradish Peroksidase Dan Karakteristiknya [Tesis]. Depok (ID): Program Studi Magister Ilmu Kimia UI

Mathew H, Punnackal VS, Kuriakose S, Kumari BS dan Manuel A. 2013. Synthesis and electrical caracterization of polyaniline-multiwalled carbon nanotube composite with different dopants. International Journal of Scientific and Research Publications. 3(8): 1-9.

Nur NM. 2017. Sintesis dan Karakterisasi Polianilinselulosa dari Tongkol Jagung sebagai Bahan Baku Elektrolit Padat Baterai [Skripsi]. Sukabumi (ID): Universitas Muhammadiyah Sukabumi.

Nurdiati D. 2015. Sintesis komposit PANI/karbon dari tempurung kemiri (Aleurites moluccana) sebagai elektroda kapasitor. Jurnal Fisika Unand. 4(1): 51-57.

Nyimas DS, Gustan P dan E. Gumbira S. 2014 Kajian pembuatan arang aktif berbahan baku bagas tebu melalui kombinasi proses karbonisasi hidrotermal dan aktivasi kimia.
Jurnal Teknologi Industri Pertanian. Vol 24 (2): 157-165.

Rao PS, Sathyanarayana DN and Palaniappan S. 2002. Polymerization of aniline in an organic peroxide system by the inverted emulsion process. Macromolecules. 35: 4988-4996.

Sharma AK, Chaudhary G, Kaushal I, Bhardwaj U and Mishra A. 2015. Studies on nanocomposites of polyaniline using different substrates. American journal of polymer Science. 5(1A): 1-6.

Sonibare OO, Haeger T dan Foley SO. (2010). Structural characterization of Nigerian coals by X-ray diffraction, Raman and FTIR spectroscopy. Energy. 35: 5347-5353.

Surianty, Akhiruddin, Ambarsari L. 2013. Studi elektrokimia polianilin komposit elektroda pasta karbon. Jurnal Biofisika. 9(2): 46-54

Taylor. 2009. Conductive Electroactive Polymers. Francis Group, LLC. Francis.

Wallace GG, Spinks GM, Kanemaguire LA and Teasdale P. 2003. Conductive Electroactive Polymers-Intelligent Materials Systems. New York (US): CRC Press.

William RA, Berlian S dan Mariana BM. 2014. Sintesis polianilina pada matriks selulosa sebagai elektrolit padat pada model baterai sederhana. JKK. 3(4): 32-38.

Yuningsih LM, Mulyadi D, Jaka AK. 2016. Pengaruh aktivasi karbon aktif dari tongkol jagung dan tempurung terhadap nilai konduktifitas. SANTIKA: Jurnal Ilmiah Sains dan Teknologi. 6(2): 531-536. 